puters are needed, not only to solve the equations of motion, but also to choose the arbitrary constants in the equations of motion by best-fitting of the experimental data.

Within the last few years it has become clear that these models are indeed greatly superior to the earlier ones. The clear and authoritative book of Launder and Spalding describing these developments, is therefore timely. It is based on lectures given by the authors at Imperial College. The slides used in these lectures, which contain basic statements, graphs or equations, are reproduced in a box at the head of each page. The verbal discussion of each slide is reproduced as text below the box.

This unusual format enabled the authors to get the book out very quickly so that it is up to date although the subject is developing very fast. It does demand unremitting concentration from the reader. If he is willing to make the effort, he will be rewarded by rapid understanding of a diffuse and difficult subject.

The exposition starts with the old eddy viscosity and mixing length models, and gives at least some space to every turbulence model which has been seriously proposed for practical work. The numerical constants which should be used in the models are quoted whenever they are known, and the model predictions are extensively compared with experimental data. Apart from its primary purpose, the book is a mine of references to the best experiments over a wide area of fluid mechanics and heat transfer problems.

The final chapter is called "Probable future developments". It anticipates the application of the model to such things as (atmospheric) cyclones and industrial furnaces, but it also tries to forecast the development of the models themselves. The forecast is of more of the same-one-point closures with constants determined from experiment. I like to think that one day we shall be able to do more than this.

When a mechanical engineer thinks he has fluid flow problems, it is chastening for him to look at the range and complexity of the situations which concern a chemical engineer. Professor Davies describes a variety of such situations. His main theme is mass transfer, and he gives particular emphasis to surface effects in two-phase flows. The book moves from one phenomenon to another, giving both description and theoretical interpretation.

Some of the descriptive material is very good, and the supporting photographs are excellent. The theoretical material is very much less satisfactory. The depth of the exposition inevitably varies, reffecting the uneven state of our knowledge. When the author does ex- pound in depth, the mathematics is ponderous and the end result is often badly out of date. I was particularly shaken to find that the most recent theory of heat transfer to a solid surface mentioned in the book is that of Prandtl (1910).

The book would mislead a novice on certain important points. However, it contains interesting material which is not readily available in book form, and a mechanical engineer who wanted to broaden his vision might well find it helpful.

D. C. Leslie

\section{Kinetic Mathematics}

Kinetic Systems: Mathematical Description of Chemical Kinetics in Solution. By C. Capellos and Benon H. J. Bielski. Pp. xii +138 . (Wiley: New York and London, August 1972.) $£ 5$.

THIS little book has been written primarily for chemists needing guidance in the mathematical techniques essential to kineticists. Its introductory chapter concludes with references to five standard textbooks on chemical kinetics. Most of the content of this monograph is available in them, usually as appendices. This fact by no means renders the present booklet superfluous. Many scientists will doubtless benefit by its compactness. Nevertheless, the complete absence of data is a fault which, one hopes, will be rectified in later editions. Consider, for example, reactions of kinetic order of five or six. To mention these numbers would be not only true and relevant but would be as jam with the powder to titillate the digestion of much that is old and inevitably stodgy.

The notation, though commendably precise, is over-elaborate, and must have given headaches to compositor, proofreader and printer alike. Mature kineticists will inevitably toy with the possibility of using the first three letters of the alphabet to denote constant compositions, and the last three letters to denote time-dependent compositions, all without superscripts, subscripts, square brackets and other frills.

Insufficient attention has generally been given to the limitation of the applicability of some of the kinetic expressions used. For example, Debye's treatment of the kinetics of reactions between ions in solution, which is reproduced in full, adopts a macroscopic permittivity, a semi-empirical distance of nearest approach, and is restricted in its validity to a single encounter in an infinitely dilute solution.

Omitted from a wide range of kinetic systems is that of the ammonium cyanate-urea reaction - a reversible second-order and first-order reaction in a time-variable ionic environment. It is historically important, biologically interesting and kinetically challenging. E. A. Moelwyn-Hughes

\section{Karst}

Karst. By J. N. Jennings. (An Introduction to Systematic Geomorphology. Volume 7.) Pp. xviii +252 . (MIT: Cambridge, Massachusetts, and London, January 1972.) $\$ 8.95$.

Karst : Important Karst Regions of the Northern Hemisphere. Edited by $\mathbf{M}$. Herak and V. T. Stringfield. Pp. xiv + 551. (Elsevier: Amsterdam, London and New York, 1972.) Dfl. 75; \$22.

THEse two books, bearing similar titles, cover a subject concerned with terrain that has distinctive characteristics of relief, drainage, and other features that arise from the solubility of rocks. Bedrock consisting of limestones, and less commonly of evaporites, such as salt or gypsum, develops in humid climate a topography of chaotic relief with closed depressions, underground streams, large caves, and dry stream valleys. These features result from solution of the bedrock by running fresh waters, including percolating phreatic waters that enlarge existing voids in the rock. The result of progressive dissolution is increased permeability that finally yields a capacity to transmit large amounts of water underground, hence giving rise to dry valleys.

The word karst derives from a German transliteration of the Slav word $\mathrm{Kr}$, meaning crag or stone. The classic site of karst is in the Dalmatian Mountains of Yugoslavia, hence the Slav and German languages enter into the meaning and definition of this specific landform.

The book by Jennings is an introduction to the geomorphology of karst. The book edited by Herak and Stringfield is a multi-authored effort in which experts from countries in the northern hemisphere wrote chapters on the karst features in their areas of study. Neither book is complete. Jennings's bias is towards karst in Australia, New Zealand, New Guinea, and Malaysia, areas with which he has personal acquaintance. The classic karst regions of Europe, North America, Java, and the Caribbean receive less attention than they deserve, or no attention at all. The book edited by Herak and Stringfield has eleven chapters on Europe, one on the United States, and one on Jamaica. Hence the lack of geographic coverage in one book is partly compensated by the other.

Both books, each in its own way, have much to offer to geologists and geographers interested in landforms, particularly to those scientists with interest in the behaviour of limestone terrain subjected to running water. Nonspecialists will be frustrated by the use of less common terms, such as dolines, poljes, hums, ponors, uvales, cockpits, grikes, tafonis, and clints, to name but a few. A glossary would have been a 